Article

\title{
An Innovative Approach to Enhancing the Sustainable Development of Japanese Automobile Suppliers
}

\author{
Chia-Nan Wang ${ }^{1}$, Ying-Fang Huang ${ }^{1}$, Thi-Nham Le ${ }^{1, *}$ and Thanh-Tuan $\mathrm{Ta}^{2}$ \\ 1 Department of Industrial Engineering and Management, National Kaohsiung University of Applied \\ Sciences, No. 415 Chien Kung Road, Sanmin District, Kaohsiung City 80778, Taiwan; \\ cn.wang@cc.kuas.edu.tw (C.-N.W.); winner@kuas.edu.tw (Y.-F.H.) \\ 2 Foxconn Electronics Inc., Bac Ninh Province 790000, Vietnam; tuantathanh@yahoo.com \\ * Correspondence: annie.lenham@gmail.com; Tel.: +886-7-8215888 (ext. 107); Fax: +886-7-8215866
}

Academic Editor: Tin-Chih Toly Chen

Received: 6 March 2016; Accepted: 25 April 2016; Published: 28 April 2016

\begin{abstract}
The Japanese automobile industry has been hit sharply by the economic downturn of recent decades. The rise in costs and decline in sales have led to serious problems in the auto industry. In order to address these issues, most companies engage in downsizing and redesigning production operations. It is crucial to investigate the time wasted by replacing assembly boards occurring in manufacturing lines. Therefore, the aim of this study was to provide an integrated approach, Teoriya Resheniya Izobreatatelskih Zadatch (TRIZ), to providing efficient solutions for the automobile industry. The first step of this methodology is to detail the technical problems using the Function and Attribute Analysis (FAA) model. Secondly, a contradiction matrix and the inventive principle were applied to find the solutions. In this study, an auto part supplier named Sumi-Hanel located in Hanoi, Vietnam, was taken as a case study; the empirical results showed that waste time had been reduced to $67 \%$, nearly 8400 square meters was saved, and a $20 \%$ cost reduction was achieved by reusing old frames. The research proves that the combination of TRIZ and lean manufacturing successfully increases production performance and reduces waste due to technological advancements.
\end{abstract}

Keywords: lean manufacturing; TRIZ; automobile industry; function and attribute analysis model; contradiction matrix

\section{Introduction}

Japan's automobile industry has made a huge impression; it is ranked very highly in terms of key export products and makes a remarkable contribution to Japan's core economy. Japanese automakers craft better quality products with fewer defects and have the world's highest reputation. The country is home to leading manufactures that have introduced highly competitive cars with advanced hybrid and fuel-saving technologies, namely Toyota, Honda, Daihatsu, Nissan, Suzuki, Isuzu, etc. [1]. Automobile manufacturing is an integrated industry because it relies on many supporting industries, referred to as automobile system suppliers, in order to produce a diversity of materials and components. Auto-related industries employed a total of 5.5 million people in 2014, covering an extremely wide range of industries from materials supply and vehicle production to sales, servicing, and freight shipping [2].

Japan is the third largest automobile producer in the world, with export of motor vehicles recorded at 4,578,078 units, a 49.3\% share of the total manufacturing volume in 2015-and this is a production increase after two years of downturn [3]. However, annual vehicle sales in Japan today are lower than they were 10 years ago, suggesting a saturated domestic market and a backdrop of long-term economic problems. Figure 1 gives a complete picture of motor vehicle exports over the past decade; 
it reflects the automotive industry's fluctuation, strongly affected by global economic crisis during 2008-2010 [2]. Most companies today are still struggling to climb out of the trough of recession in order to retain market share and not be surpassed by other emerging economies such as the Chinese and Indian automobile industries [4,5]. Japan's past successes and current challenges are most apparent in the nation's automakers, so the country has accordingly attracted the attention of many researchers, both academicians and practitioners, as the economic situation can have serious implications on the further development of the automobile industry [6-8].

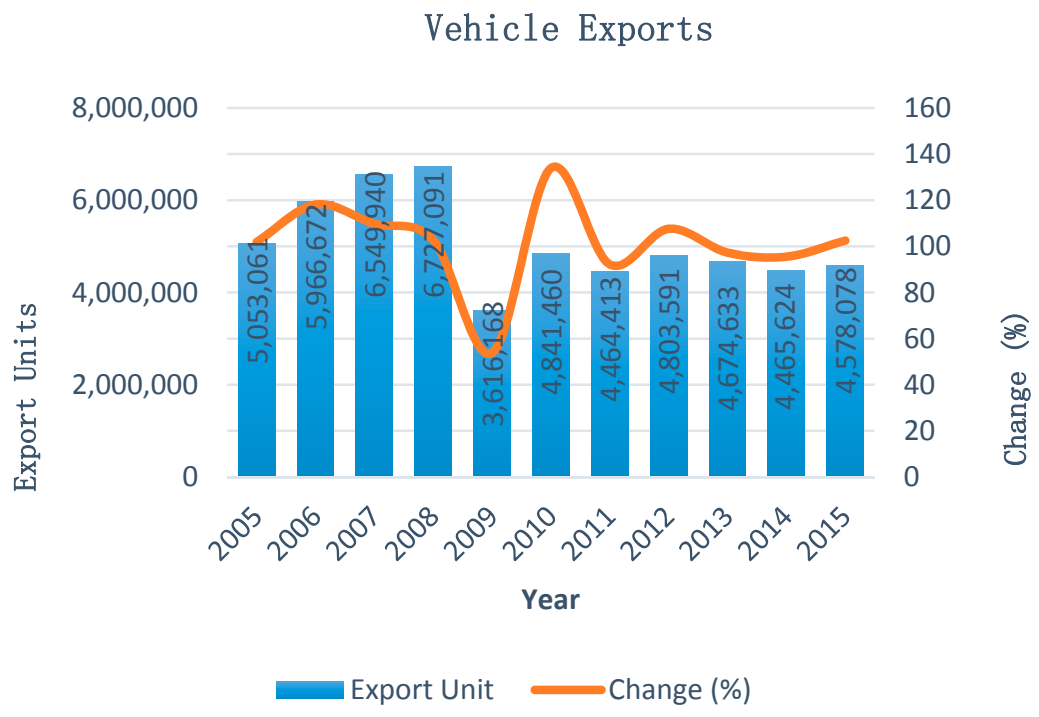

Figure 1. Motor vehicle exports.

During the stagnation of the Japanese economy for over a decade, Toyota Motor Company retained about $50 \%$ of its global production in Japan and ranked as the world's most successful automaker, totally outperforming its competitors in terms of quality products and reliable services by applying lean production $[9,10]$. Lean manufacturing has been used in a variety of industries as a creative method that eliminates waste while increasing productivity $[11,12]$. Companies can predict short supply lines based on a lean method that delivers small batches of components to the assembly line steadily without interruption [13]. Lean manufacturing provides ideas for companies to solve problems and correct product specifications as required. This business model helps automakers reduce inputs and assembly costs, and produce better quality products. Today's leading companies like Toyota, Ford, Dell, and FedEx are creating their business models based on lean thinking and are gaining significant benefits that continue to enhance their success in the global market [14,15].

As an extension of the Japanese automobile industry, the auto parts industry depends on consumer demand for vehicles in order to succeed. The automotive industry crisis of 2008-2010 was a part of a global recession; it seriously affected automakers and their supply chains. Production cuts by automakers caused severe challenges for auto part manufacturers. After the influence of the financial downturn and decline of sales, industry analysts had suggested that suppliers should run at least $80 \%$ capacity compared to original production in order to make a profit; in fact, they only reached $50 \%-60 \%$ production capacity in 2009 [16]. Many companies have faced serious problems of excess labor, overcapacity, scarce resources, and the rising cost of input. In order to cope with these issues, most firms are required to further restructure operations and downsize product lines. However, the renewal process for an industry is never easy, and might be affected by internal innovation capability and external linkage according to automakers' requirements and different viewpoints in today's fiercely competitive globalized world. 
As an original equipment manufacturer (OEM), Sumi-Hanel, the wiring system supplier for Japanese automakers, faced lots of difficulties during the automobile industry crisis and Japan's recession. The reduction in sales demand made many conveyors run at low production. In order to eliminate the waste of human resource and production costs, two conveyors were combined into one. However, the combination meant the average efficiency in 2009 was only $80 \%$. This means that efficiency dropped by $15 \%$ compared to the previous year, according to the report of the Department of Engineering. Sumi-Hanel has focused on improving production by applying the lean manufacturing model for many years; however, lean tools seem to be not scientific enough to find and solve realistic problems of inefficient factors. TRIZ methodology has been applied in many automobile companies in various sections of manufacturing activities. However, each sector is always impacted by excess production costs. Therefore, this research employs the application by combining TRIZ and lean manufacturing to achieve cost improvement and technical innovation by using TRIZ methodology under lean manufacturing concepts to find all problems occurring in every assembly line. Finally, replacing the assembly board was investigated as the main reason. This paper defines the problem existent in the replacing assembly board using the Function and Attribute Analysis (FAA) model, then engages the contraction matrix and inventive principle to find and solve problems, which enhances the production efficiency for the firm by reducing use in the manufacturing process and ensuring the highest standards of quality and safety of auto parts.

TRIZ was developed in 1946 by Altshuller, a Russian scientist who initiated the theory of inventive problem solving [17]. It is an effective method for analyzing problems and developing innovative solutions. TRIZ has the ability to not only be prepared for methods, but also to create them. Firstly, the paper proposes an innovative approach that integrates TRIZ into lean concepts to apply to manufacturing processes in the automotive industry. Finally, this research provides a valued method for managers with regards to manufacturing performance, along with insight into the best pathways for companies to improve the sustainable manufacturing by using TRIZ and lean manufacturing. The aim of this study is to provide an integrated TRIZ approach into lean thinking to generate innovative solutions for the automobile supplier, reduce the time of changing board, and drive costs down for setting up new conveyors. Sumi-Hanel, a supplier of Japanese automobile parts, was taken as an example. The goal of the research is to minimize the waste time in replacing the assembly board and increase productivity. Inventive principles and a contradiction matrix were used in this study as the concept of innovative system analysis. The scope of this research focuses on improving productivity. Therefore, the authors only compare the results before and after improvement. This is just the first step of improvement. However, continuously enhancing productivity for sustainable development is necessary by applying more methods in the future.

The rest of this paper is organized as follow. Section 2 begins with background, introducing lean manufacturing and giving a general overview of TRIZ. Section 3 presents a case study and discussion. Some conclusions are made in Section 4.

\section{Background}

\subsection{Lean Manufacturing}

Lean manufacturing, also known as lean production, is a set of tools and methodologies intended to eliminate all waste in the entire system [18]. Today, lean manufacturing is adopted in a variety of industries in order to significantly reduce inventory in the supply chain, increase productivity, and improve the quality of the products. Lean manufacturing focuses on investigating defects and wastage, cycle times, inventory levels, labor productivity, utilization of equipment and space, flexibility, and output. The main outcomes of lean manufacturing are a reduction in time waste and unnecessary resources due to machine setup, product changeover, or long production lead times. The main benefits of lean manufacturing are lower production costs, increased output, and higher quality products [19]. 
Lean manufacturing refers to the elimination of any kind of waste that diminishes value for manufacturers and businesses. Lean methods has been developed much of its use by Japanese automobile manufacturer Toyota. The Toyota Production System manual, written by Taiichi Ohno, published for the second time in 1994, explained the foundation of lean manufacturing [20]. These principles guided Japanese companies to be successful and become the world leaders in the automobile industry. Ohno identified seven main types of waste: over-production, defects, inventory, transportation, waiting, motion, and over-processing [20]. The lean production system ensured companies' position as industry leaders, and its principles were adopted by companies in many countries.

Some applied innovation researchers have put much effort into studying Toyota's performance in order to identify the realistic outcomes of lean manufacturing. It can be pointed out that the creative methods of Toyota production system (TPS) are not just the use of inventory reduction, setup reduction, and cost reduction. Rather, the backbone of TPS is integration of all solutions in the entire system to optimize the overall manufacturing process. Womack and Jones developed the lean concept further based on two famous books, The Machine that Changed the World and From Lean Production to the Lean Enterprises, in the 1990s [21,22]. They studied 90 automobile assembly factories in 17 countries to understand how the Japanese succeed in manufacturing. By applying lean manufacturing, the firms improved production by focusing on the elimination of all waste. Kamath and Liker (1994) indicated that Toyota and other Japanese automakers set clear and understandable goals for their suppliers based on their capacity and mutual alignment [23].

Needless to say, few manufacturers have imitated Toyota successfully, even though the firm has announced its technical practices. It is clear that the secret of Toyota's success is based on tight principles of industrial engineering, namely simplification, standardization, and systematization, which are supported by scientific requirements, and combine with innovative aspects to achieve waste reduction and cost reduction while simultaneously increasing outputs. Therefore, in order to implement the lean approach, it is necessary to undertake an in-depth study of companies following the fundamental principles of TPS over time.

\subsection{Theory of Inventive Problem Solving (TRIZ)}

\subsubsection{A General Overview of TRIZ}

TRIZ developed extensively in the Soviet space and defense industries during World War II beginning in 1946; it then began to popularize and further developed in countries all over the world in the following decades [17]. Today TRIZ has been used by many leading companies such as Ford, GM, Intel, and Xerox in order to enhance their global competitiveness. Global Samsung electronics recovered from the verge of bankruptcy after applying TRIZ, which helps to transform unidentified situations by solving technical problems and securing core patents [24,25]. TRIZ suggests strategies and patterns for resolving contradictions in both time and space. Although originally developed for technical applications, today TRIZ has gradually developed to generate breakthrough ideas for the manufacturing and service industries.

TRIZ is an undoubtedly powerful problem solving method that consists of technical evolution, applying scientific methods in order to get the best results without harming the system [26]. TRIZ gives creative access to the knowledge and the best innovative experience of technology in the world. TRIZ is designed to carry out and add structure to natural creativity rather than replace it. It allows researchers to define and then solve any given problem in the system. TRIZ aims to find problems and solve those problems-whether they be technical or non-technical, simple or complex [26]. The advantage of TRIZ is that it actively transforms unwanted or harmful elements of a system into useful resources. There are different problem solving methods in TRIZ that can be used together or separately [27]. Generally, the innovative processes of TRIZ are to investigate realistic problems, define them, generalize ideas by finding the contradictions, and finally apply those general solutions to the specific problem [28]. 
Mann, 2002 depict the systematic creativity process of the TRIZ method, which consists of four major steps as shown in Figure 2; the steps are: define, select tool, generate solution, and evaluate. These steps can be a looping process until the solution is obtained [29].

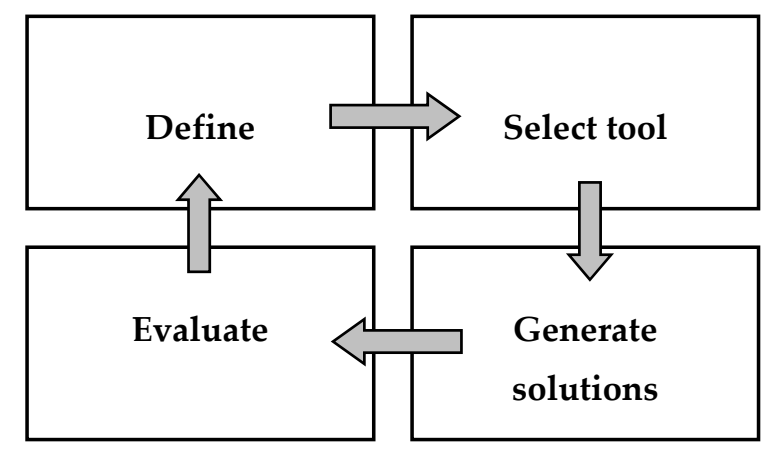

Figure 2. Four major "Systematic Creativity" steps.

The first step, "define," asks the question: "what are the problems in the system?" TRIZ provides five tools to define a problem: problem explorer, ideal final result, function and attribute analysis (FAA), S-curved analysis, and perception mapping. The second step, "select tool," determines the most appropriate problem solving techniques for the particular problem. In other word, different problems need different tools to generate different solutions. The third step, "generate solutions," is the stage where many options are generated by using TRIZ tools such as substance-field analysis, technical contradiction/inventive principle, psychical contradiction, trends, resource, trimming, knowledge/effect, ideal final result, and subversion analysis. Each tool also includes many systematic steps to generate solutions. The last step, "evaluate," identifies the best solution from the ones generated in the third step. TRIZ offers two main ways to evaluate the result of the solution, which are quantity and quality.

In order to analyze problems, it is necessary to investigate the interactions between all the components of an existing system. Therefore, in this paper, the FAA model is employed to find the focus and key problems as a first step [30]. The FAA model seeks out such problems by enabling researchers to more adequately describe the function analysis model in terms of how it is affected by changes in time. This model aims to identify in detail what the solution is expected to do and what its attributes will be. The FAA model not only advises researchers to understand the function of the components in the system but also encourages them to identify the harmful, ineffective, and excessive relationships as well.

Among the set of tools of the third step, the contradiction matrix and the 40 inventive principles are the most powerful tools, based on more than 400,000 patents analyzed by Altshuller, and it is a very effective series of solutions for deriving new ideas for products [31]. The main findings of TRIZ are special processes for creating new concepts and tools as part of TRIZ to become familiar with parameters contained in the matrix in order to generate strategies and solve technical problems.

\subsubsection{Function and Attribute Analysis}

Function and attribute analysis (FAA) is one of the three essential elements of the problem definition process given by Mann, 2007 [30]. It represents a systematic method by which it is possible to analyze the detailed workings of an existing system. In terms of managing complexity, it is the most comprehensive of the three. A completed FAA model presents an important lead into knowing how to approach the improvement of systems. Successful function analysis modeling demands a process in which components are defined and then relationships between those components are established. In terms of defining the positive relationships, the method is useful because in many situations this will be the first time people have viewed the system under evaluation from such a functional perspective. 
In terms of the subsequent identification of harmful, insufficient, or excessive relationships in the system, this is where the user is identifying where problems exist. A completed FAA model offers a link into the select part of the systematic creativity process. It is also a document that should live with the system as it evolves over time.

The examining of FAA is through a simple system that consists of two components: an optical lens and an abrasive block used to polish the lens. The first step in producing a function analysis picture of this system is to identify the components present. Each of the components is drawn in a box. The second step then involves thinking about what the functional relationships between the different components are and defining them as directional arrows between the component boxes. The two steps are shown in Figure 3 [30]. The most important points here are to use simple noun-verb-noun relationships wherever possible, and to express the relationship using active verbs. These rules will help to tap into the solution parts of TRIZ more easily.

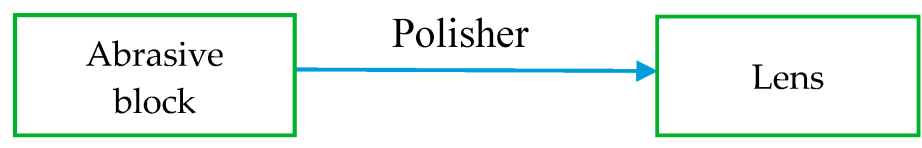

Figure 3. Function analysis representation of a two-component manufacturing system.

\subsubsection{Contradiction Matrix and Inventive Principles}

In TRIZ, contradiction is one of the key concepts that formulate problems and signpost a truly innovative approach. TRIZ provides 40 principles to solve both technical and physical contradictions, complete with descriptions of the detailed solutions contained in each principle [32]. The inventive principles are a central part of the TRIZ philosophy for problem solving and its tools help to actually eliminate compromise [33]. Given the importance of eliminating contradictions, the basic form for tool generation is a two-dimensional matrix, each side of which features the aforementioned parameters relevant to the solving of engineering, scientific, or design problems. The resulting matrix structure contains 39 different parameters. The contradiction matrix of TRIZ is mainly composed of 39 parameters and 40 inventive principles; the rows aim to present the improving feature parameters and the columns are intended to represent the worsening feature parameters, so a pair of conflicted parameters was composed [34]. Thus, the matrix element they correspond to is the 40 inventive principles that are able to resolve these conflicts. An excerpt of the contradiction matrix is shown in Table 1 [30].

Table 1. An excerpt of the contradiction matrix.

\begin{tabular}{|c|c|c|c|c|c|c|}
\hline $\begin{array}{ll} & \text { Worsening } \\
\end{array}$ & $\begin{array}{l}\text { 1. Weights of } \\
\text { Moving Object }\end{array}$ & $\begin{array}{c}\text { 2. Weight of } \\
\text { Stationary Object }\end{array}$ & $\cdots$ & $\begin{array}{l}\text { 23. Loss of } \\
\text { Substance }\end{array}$ & $\cdots$ & $\begin{array}{c}39 . \\
\text { Productivity }\end{array}$ \\
\hline 1. Weights of moving object & & & & $3,5,31,35$ & & $3,24,35,37$ \\
\hline 2. Weight of stationary object & & & & $5,8,13,30$ & & $1,15,28,35$ \\
\hline 9. Speed & $2,13,28,38$ & & & $10,13,28,38$ & & \\
\hline 39. Productivity & $35,26,24,37$ & $28,27,15,3$ & & $10,23,28,35$ & & \\
\hline
\end{tabular}

Altshuller indicated that inventors usually have problems of technical contradiction and physical contradiction when working on engineering projects [35]. Technical contradiction means that parameter " $\mathrm{A}$ " is changed when " $\mathrm{B}$ " is changed at the same time in a system. The problem with technical contradiction can be solved through a contradiction matrix and the corresponding inventive principle. Figure 4 shows that parameter " $A$ " can improve without worsening parameter " $B$ " by reducing the contradiction [36]. Conventional solutions usually propose a compromise between the "improving" and "worsening" parameters. An innovative solution is achieved by resolving the technical contradiction without compromise and tradeoff [37]. Physical contradiction means that the contradiction relates to physical properties of an element, such as big and small, cold and hot, long 
and short, etc. Altshuller proposed that the physical contradiction is normally managed by separation in time, separation in space, system transformation, and phase transition [35]. In others words, one problem exists in one conflict at least. It is a technology contradiction or a physical contradiction. When a contradiction is resolved, it has produced a new technology as well.

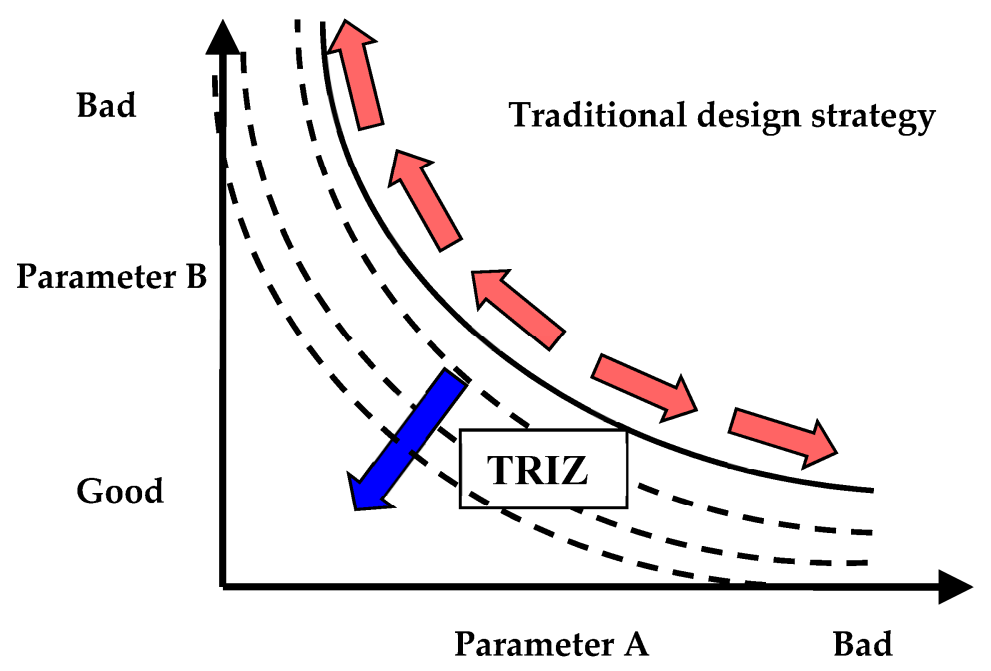

Figure 4. Different to compromise or tradeoff: TRIZ improvement.

\subsection{Using TRIZ under Lean Manufacturing Concepts}

There are many general similarities between TRIZ and lean manufacturing concepts. Both of them are aimed at improving the manufacturing process by taking a significant amount of time to define the problems, look forward to understand the truth, and solve those problems in order to eliminate defects and optimize the use of available resources [38]. Its purpose is to bring about efficiency, coordination, and control of the natural environment.

However, TRIZ focuses on realistic resources in details that can be solved, whereas lean manufacturing uses the entire system to find a feasible solution and how to go through with it. TRIZ sets up the goal of "perfection" to identify what is going wrong with the current system while lean manufacturing looks at future ideas in order to implement its processes. The purpose of lean manufacturing is to eliminate waste, which is considered one of the main problems of an unhealthy system. In TRIZ, the problems are fully addressed in relation to the waste that occurred historically.

The similarities create overlap between TRIZ and lean manufacturing, whereas the differences are reason for mutual assistance in order to find the best solutions [39]. Therefore, this paper proposes a connected thinking with TRIZ ideas based on lean implementation. The combination between TRIZ and lean manufacturing results in a perfect method to accomplish tasks they may not have been able to tackle individually.

\section{Case Study and Discussion}

\subsection{Case Study}

The aim of this study is to investigate wasted time and inefficiencies in manufacturing systems, such as has occurred in many automobile companies in the past decade. This cannot be attained without taking into account specific issues in an individual company, especially for OEM companies, which often drive up the cost of finished products through unnecessary factors. Therefore, this study employs the example of Sumi-Hanel wiring system supplier in order to focus on improving the production efficiency of the replacing assembly board and accelerating manufacturing lines in general. Through an explorative case study and the methods given in previous section, the paper will be a good foundation for other companies in the same industry that plan to improve their productivity 
by applying a combined TRIZ and lean manufacturing approach. The findings of this study may be helpful for upcoming research in the area of sustainable manufacturing. Despite the effectiveness of this innovative approach, it is not easy to achieve success by combined TRIZ and lean manufacturing processes if companies only focus on tools and methods but overlook what problems might appear in the course of manufacturing. The truth is that one successful case might not be generalized to the overall industry. However, this exploration could be a new direction for solving this kind of industrial problem.

The Japanese have a strong foothold in the automobile industry and they are pioneers in establishing external bases for automotive and auto-supporting industries. In order to make the results as effective as possible, this paper selects the Sumi-Hanel Wiring System Co., Ltd. located in Hanoi, Vietnam, is Japan's OEM automobile largest supplier, which manufactures wiring system products such as engine wiring systems, floor wiring systems, door wiring systems, and panel wiring systems for Suzuki, Toyota, and Daihatsu cars. The quantity of conveyors and customers are shown in Table 2.

Table 2. Sumi-Hanel's customers and types of conveyor.

\begin{tabular}{cccccc}
\hline Type & Customers & Suzuki & Toyota & Daihatsu & Total \\
\hline \multirow{2}{*}{} & & & & & \\
& Floor & 0 & 13 & 0 & 13 \\
Engine & 7 & 3 & 1 & 11 \\
Panel & 2 & 1 & 0 & 3 \\
Door & 0 & 1 & 0 & 1 \\
Total & 9 & 18 & 1 & 28 \\
\hline
\end{tabular}

\subsubsection{Assembly Flowchart}

The assembly flow chart is shown in Figure 5.

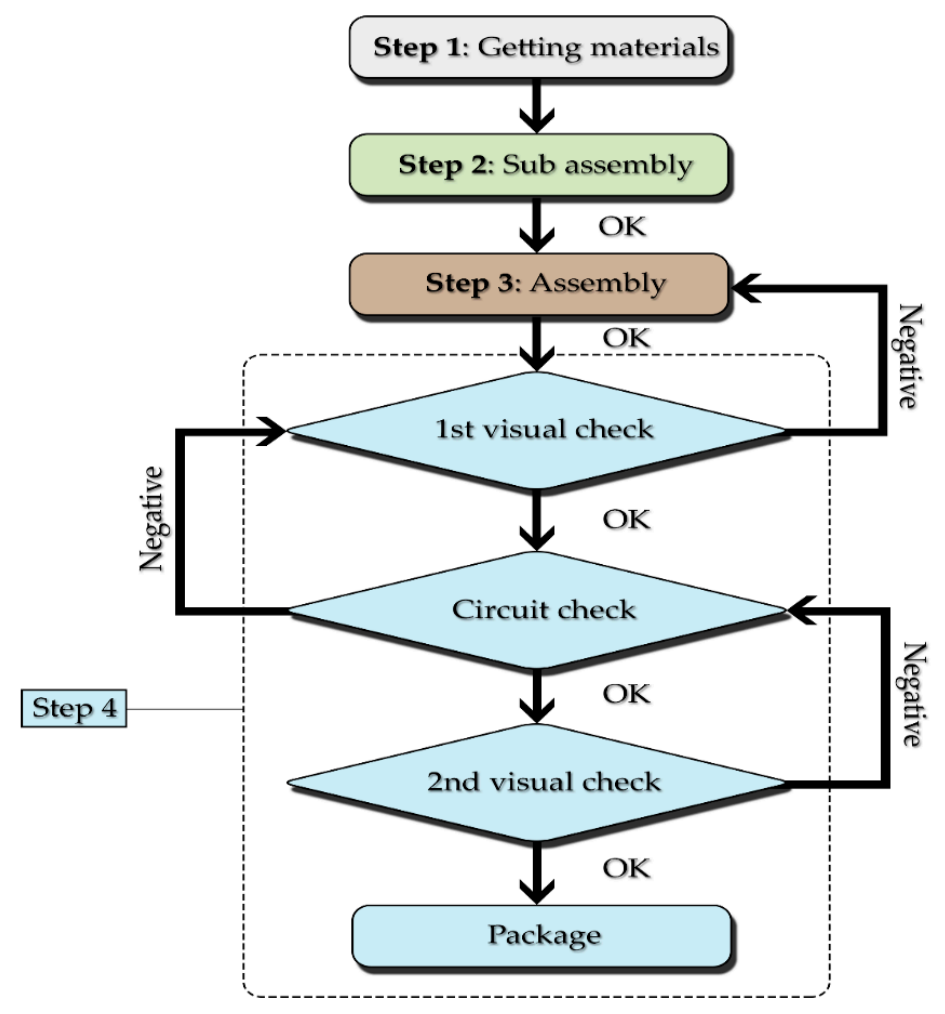

Figure 5. The assembly flow chart. 
- $\quad$ Step 1: Getting materials

Assembly tasks start with getting materials and wires from the material coordinator section, and the cutting and crimp section. Materials include connectors, clamps, clips, vinyl tubes, and poly vinyl chloride (PVC) sheets. Wires include single wire, shield wire, and twisted wire. These wires are cut and crimped terminals.

- $\quad$ Step 2: Sub assembly

In this step, operators directly insert the terminals of wires into connectors and press them gently into the slots as shown in Figure 6.

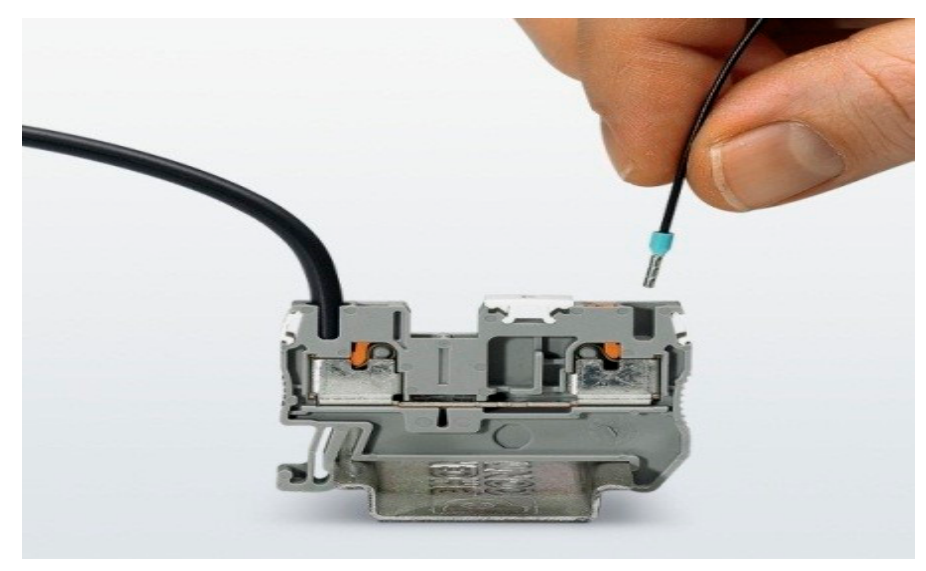

Figure 6. Inserting terminal into connector.

- Step 3: On assembly manufacturing lines, operators manually attach clamps, PVC sheets, and vinyl tubes and tape the wires together as shown in Figure 7.

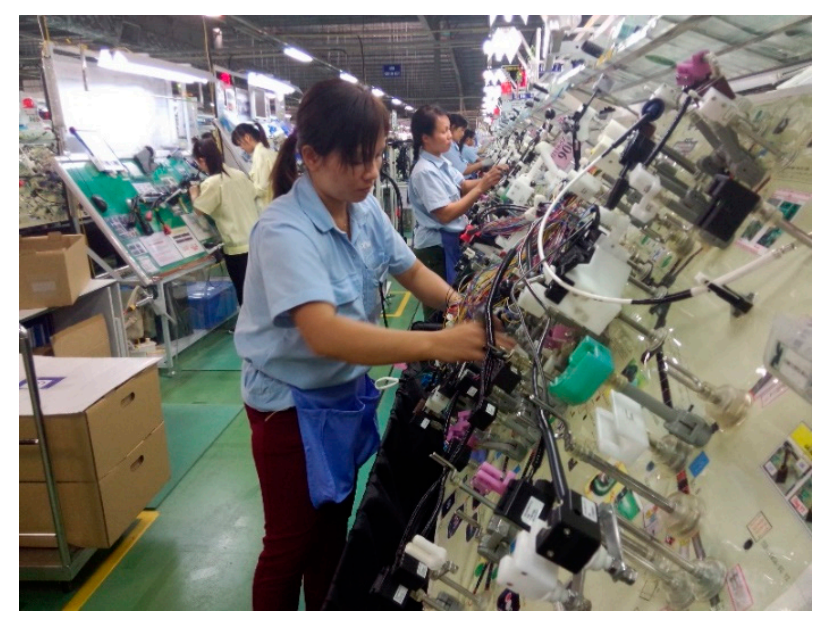

Figure 7. The operators are working on a conveyor.

The quantity and quality of each assembly board in the manufacturing lines are based on the characteristics of products; all aim to eliminate the sources of defects and errors in all processes. For example, there are only 10 frames in a long conveyor of floor wiring systems, whereas an engine size is short and contains 20 frames in a conveyor. The layout of an assembly conveyor is shown in Figure 8, which introduces the layout of YGO engine conveyor. In one engine conveyor, the first five operators start to work from station 1 to station 5 , which has responsibility for laying out sets of wires 
on the board and inserting the waiting terminals into the connectors. To continue the line, the main assembly tasks are implemented by six final operators from station 6 to station 11 . At these stations, the operators attach the clamp, fix the tape, bind the tape, thread the grommet, etc.

- $\quad$ Step 4: Quality assurance

In this step, lean manufacturing concepts are applied to raise the quality level. After all the assembly steps are done, products must be checked by six inspectors in order to ensure the quality according to automakers' standards. At the first visual checkpoint, two inspectors check the dimensions and color of the products by comparing with a master product. Two other inspectors undertake the circuit check; the use of other design currents for all the circuits has been determined, and it is necessary to check that the limitation on voltage drops is met. The products are checked one last time before packing at the second visual checkpoint. These inspectors must re-check the components to make sure the terminals and connectors are not broken after the previous steps and the packing boxes are clean and clear.

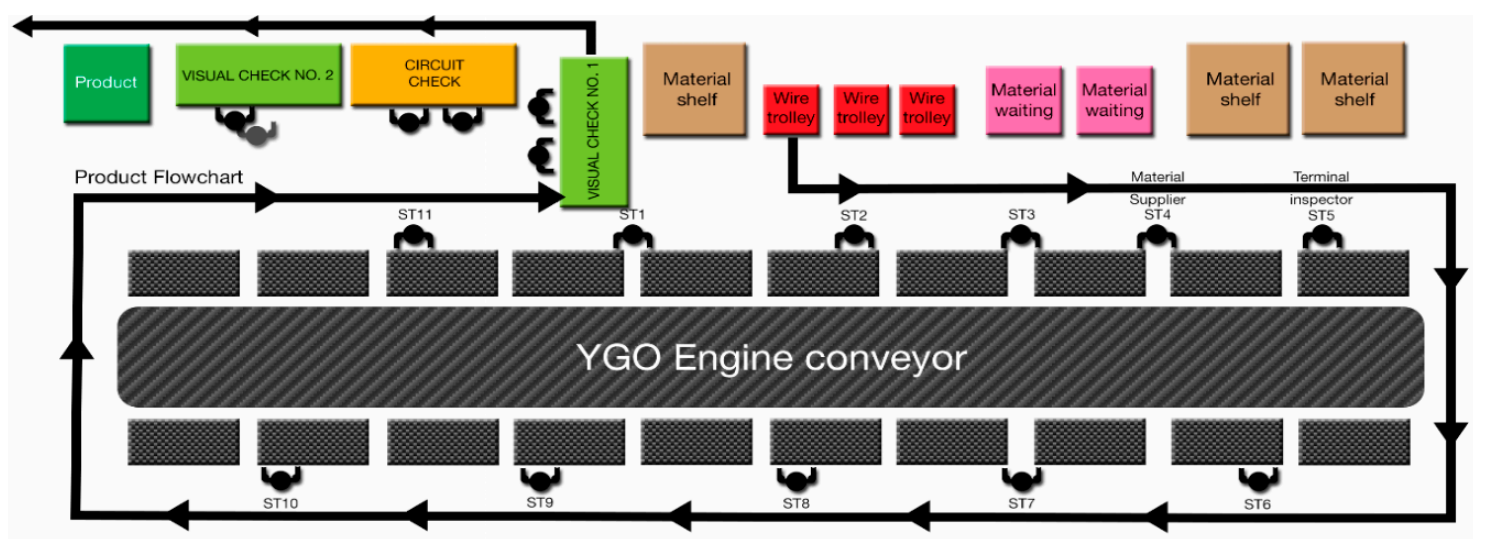

Figure 8. The layout of the YGO engine conveyor.

\subsubsection{Flexible Assembly}

The production organization is based on the product specifications. If there is only one model of product in the conveyor, the production is continuous and simple. What happens when one conveyor has several products? The production is more complex. It is crucial to analyze a system and define the harmful, insufficient, and excessive relationships among them. Several types of board are required and it sometimes takes time to change the board. In this paper, the Suzuki engine conveyor was taken as an example. There are five product models in this conveyor: 36065-65K00, 36065-65K30, 36065-65K40, 36065-65KA0, and 36065-65KC0. This conveyor has two types of board:

- $\quad$ Type 1 is used for 36065-65K00, 36065-65K30, and 36065-65K40. There are 10 boards in this type.

- $\quad$ Type 2 is used for 36065-65KA0 and 36065-65KC0. There are 20 boards in this type.

There are two type of assembly board. Figure 9 shows that there are only 20 frames in one round conveyor and each frame can only bring one board. Therefore, 20 boards are used at the same time and 10 boards are always in the waiting area. Figure 10 shows a schematic illustration of the board and frame structure. In order to complete the assembly schedule shown in Table 3, the board ratio is changed daily by the leader; this example is for November. 


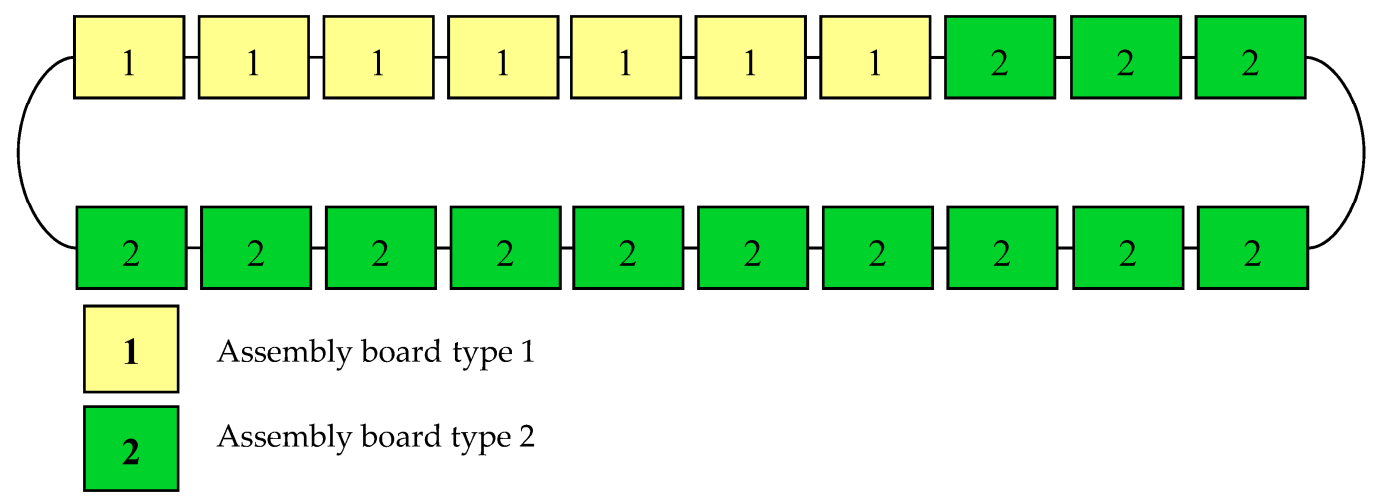

Figure 9. Layout of assembly board in conveyor.

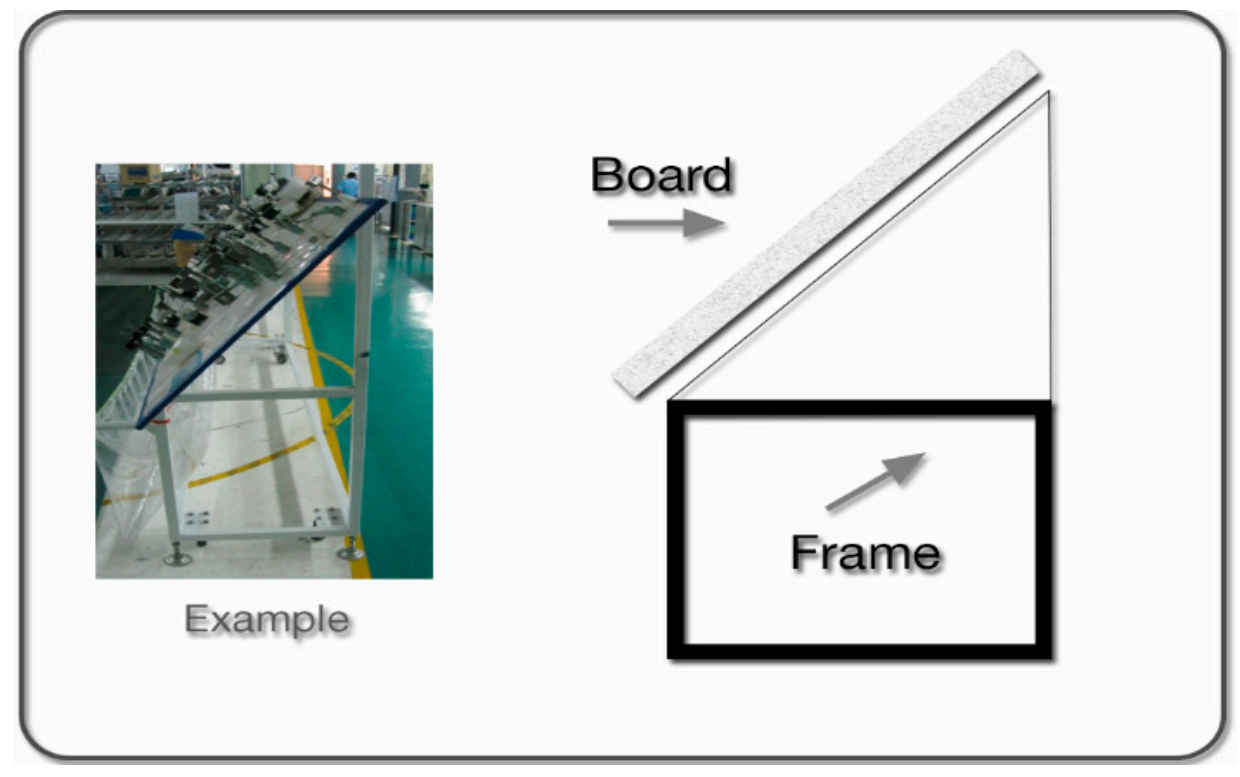

Figure 10. Schematic illustration of board and frame structure.

Table 3. Assembly schedule of SUZUKI WAGON engine.

\begin{tabular}{|c|c|c|c|c|c|c|c|c|}
\hline $\begin{array}{c}\text { Wire Harness } \\
\text { No. }\end{array}$ & $\begin{array}{l}\text { Board } \\
\text { Type }\end{array}$ & $\begin{array}{c}16 \\
\text { November } \\
\text { Tuesday }\end{array}$ & $\begin{array}{c}17 \\
\text { November } \\
\text { Wednesday }\end{array}$ & $\begin{array}{c}18 \\
\text { November } \\
\text { Thursday }\end{array}$ & $\begin{array}{c}19 \\
\text { November } \\
\text { Friday }\end{array}$ & $\begin{array}{c}20 \\
\text { November } \\
\text { Saturday }\end{array}$ & $\begin{array}{c}21 \\
\text { November } \\
\text { Sunday }\end{array}$ & $\begin{array}{c}22 \\
\text { November } \\
\text { Monday }\end{array}$ \\
\hline $36065-65 \mathrm{~K} 00$ & 1 & & & & & & & \\
\hline $36065-65 \mathrm{~K} 40$ & 1 & 175 & 175 & & 175 & 100 & 100 & 130 \\
\hline 36065-65KА0 & 2 & & & & 125 & 40 & 150 & \\
\hline 36065-65КС0 & 2 & 325 & 325 & 500 & 200 & 285 & 200 & 350 \\
\hline \multicolumn{2}{|c|}{$\begin{array}{l}\text { Assembly board ratio } \\
\text { (Type } 1 \text { /Type } 2 \text { ) }\end{array}$} & $7 / 13$ & $7 / 13$ & $0 / 20$ & $7 / 13$ & $7 / 13$ & $4 / 16$ & $4 / 16$ \\
\hline
\end{tabular}

According to the schedule shown in Table 3, boards need to be replaced as follow:

- On 18 November, seven boards must be replaced.

- On 19 November, seven boards must be replaced.

- On 21 November, three boards must be replaced.

Therefore, 17 boards were replaced in total within a week. Four steps are required to replace the assembly board: the replacing of the old board, preparation of the assembled frame, setting up 
another board on the frame, and finally storing the boards in awaiting area, as shown in Figure 11. The minimum required time of replacement for each board is $15 \mathrm{~min}$; therefore it takes $255 \mathrm{~min}$ in total to replace 17 boards. At the same time, 153 products could be made in 15,300 s if $100 \mathrm{~s}$ are assumed to complete one product. In order to complete 500 products per day, the operators must work overtime. Sumi-Hanel has 28 conveyors, so several kind of boards are used on one conveyor with different kinds of products. The more types of board that are used, the more complex the conveyors are, which makes it difficult to control the quality of products. Table 4 gives a summary of product types and board types in the Sumi-Hanel system, given by the internal department of production engineering.

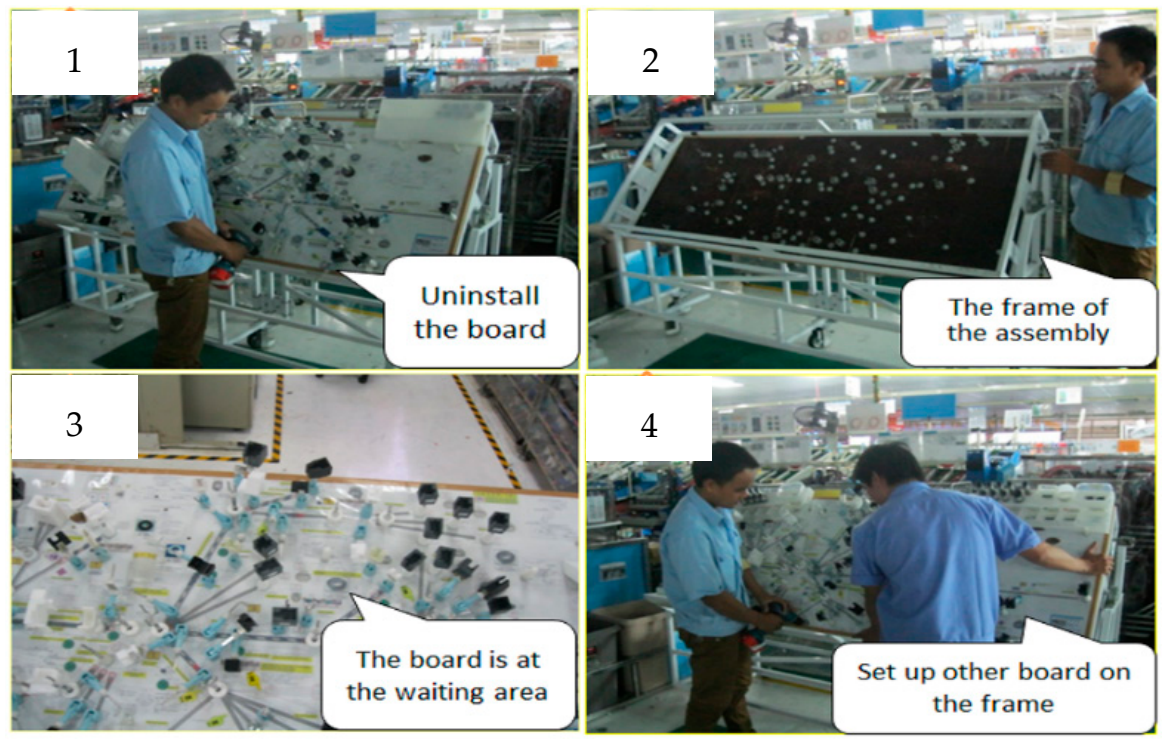

Figure 11. Changing assembly board.

Table 4. Summary of product types and board types used by Sumi-Hanel.

\begin{tabular}{|c|c|c|c|c|c|}
\hline No. & Name & Product Type & Board Type & Total Board & Total Frame \\
\hline 1 & Voxy & 1 & 1 & 12 & 12 \\
\hline 2 & Voxy/Saion EG & 3 & 2 & 24 & 12 \\
\hline 3 & YT2 EG & 6 & 5 & 20 & 20 \\
\hline 4 & YGO INST & 23 & 1 & 20 & 20 \\
\hline 5 & YGO EG & 6 & 5 & 20 & 20 \\
\hline 6 & Wagon/YK1/Alto EG & 8 & 6 & 40 & 20 \\
\hline 7 & YGO1 EG & 6 & 3 & 24 & 20 \\
\hline 8 & YGO 2 EG & 6 & 3 & 24 & 20 \\
\hline 9 & Ipsum/Saion Floor & 16 & 2 & 28 & 14 \\
\hline 10 & Alto/YT2 Inst & 13 & 2 & 40 & 20 \\
\hline 11 & Swift EG & 12 & 5 & 18 & 14 \\
\hline 12 & Isis/EK Wagon Floor & 30 & 2 & 28 & 14 \\
\hline 13 & Hijet EG & 3 & 2 & 16 & 10 \\
\hline 14 & Vitz Floor & 31 & 2 & 16 & 10 \\
\hline 15 & Vitz 5DR/Yaris Floor & 18 & 1 & 10 & 10 \\
\hline 16 & Ractis Floor & 11 & 3 & 14 & 10 \\
\hline 17 & Belta/Vios Floor & 10 & 2 & 13 & 10 \\
\hline 18 & YY3 EG & 17 & 4 & 19 & 14 \\
\hline 19 & YY3 EG new & 17 & 4 & 18 & 14 \\
\hline 20 & EK Wagon Door & 8 & 8 & 16 & 10 \\
\hline 21 & Move EG & 3 & 1 & 20 & 20 \\
\hline 22 & Premio Floor/Yaris EU Floor & 17 & 2 & 28 & 14 \\
\hline 23 & Highlander Floor & 19 & 1 & 14 & 14 \\
\hline 24 & Highlander/Tundra Inst & 32 & 3 & 28 & 14 \\
\hline 25 & Isto/Vios Floor & 18 & 3 & 26 & 14 \\
\hline 26 & Yaris Floor & 10 & 1 & 14 & 14 \\
\hline 27 & 630L Floor & 16 & 1 & 14 & 14 \\
\hline 28 & 640L Floor & 36 & 1 & 14 & 14 \\
\hline
\end{tabular}




\subsection{Definition}

The first step in the TRIZ methodology requires answering what are the problems, what benefits are we looking to achieve, and what are the functions and attributes contained in the current system? In this study, one useful TRIZ tool, function and attribute analysis (FAA), was employed to analyze and specify the problems that occurred in the assembly section. The evolution of the system will be guided by the removal of the harmful relationships in the system, and improvement of the insufficient ones. This kind of function and attribute analysis model is helpful in managing the complexity surrounding system design and the improvement of that system. Firstly, identify the components present; then define the positive functional relationships; define harmful, insufficient, and excessive relationships; and consider the time-variant issues. According to the function attribute analysis, the situation of the assembly is illustrated in Figure 12.

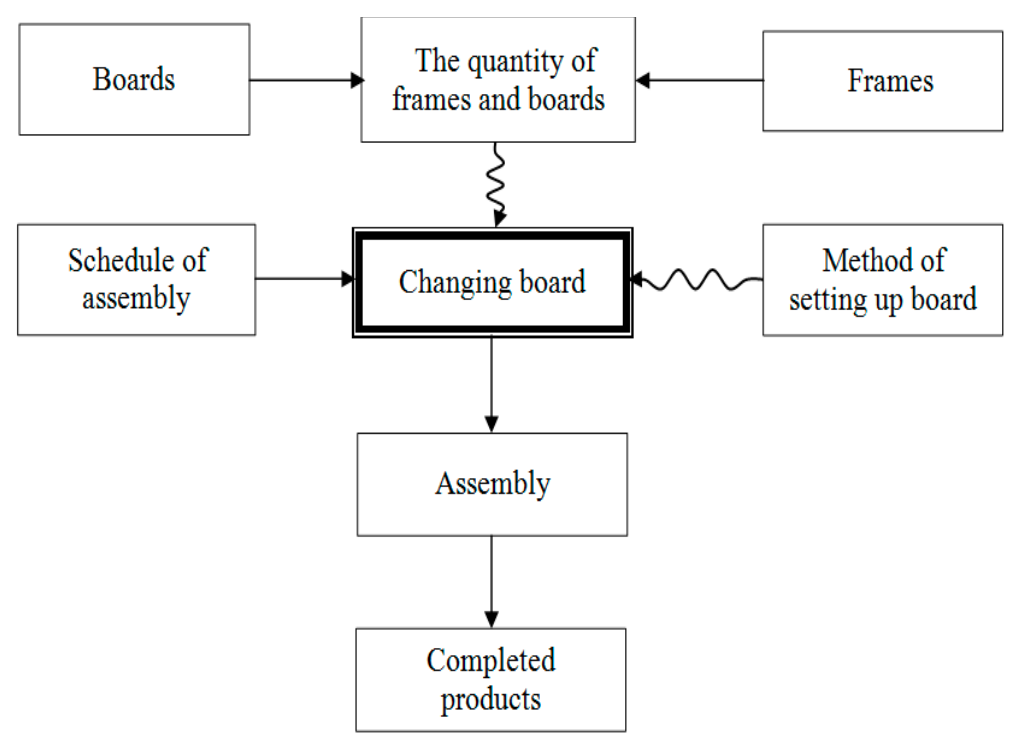

Figure 12. The FAA model to define the problem.

In Figure 12, straight lines denote "useful," wavy lines indicate "harmful," and dashed lines show "insufficient." Therefore, two factors were defined in this paper. The first problem that occurred in the assembly section was that the quantities of frames and boards are not the same. There are more boards than frames; therefore it is necessary to replace the board when making another type of product. The quantity of frames depends on the assembly area and cannot be changed. The quantity of boards optimizes the costs and benefits. Therefore, the main question behind this problem is the optimal quantity of boards- "is it possible to make boards that can be used to make all types of products? How can we make them?" The second problem is technical skills for how to change boards properly. In manufacturing lines, screws and a drilling machine are used as tools to remove and set up a board on a frame, as shown in Figure 11. However, it is a manual skill and takes about $15 \mathrm{~min}$. Therefore, the question emerges: "Is there a faster method for attaching boards into the frame without using screws and drilling machines?"

\subsection{Select Tool}

Select tool is the second step of the TRIZ process. It determines the most appropriate problem solving techniques for the particular problem. The contradiction tools are a very important part of TRIZ, which was outperformed by 39 engineering parameters and the suggestion of 40 inventive principles listed in this matrix. When two different engineering parameters conflict with each other, it means that the system has technical contradictions; TRIZ resolves the contradictions in the process, as shown in Figure 13. If one of the engineering parameters improves, the other one will become 
worse. Therefore the system needs to be better from the suggestion of the inventive principles in the contradiction matrix. As all of the 39 engineering parameters from TRIZ are investigated for this original problem of changing the board, what needs to be improved in the system are three parameters: \#15-“duration of action of moving object"; \#26-“quantity of substance/the matter"; and \#35- "adaptability or versatility." Those parameters that will get worse for the system are \#1—“weight of moving object" and \#36- "device complexity." The contradiction matrix can be summarized as shown in Table 5.

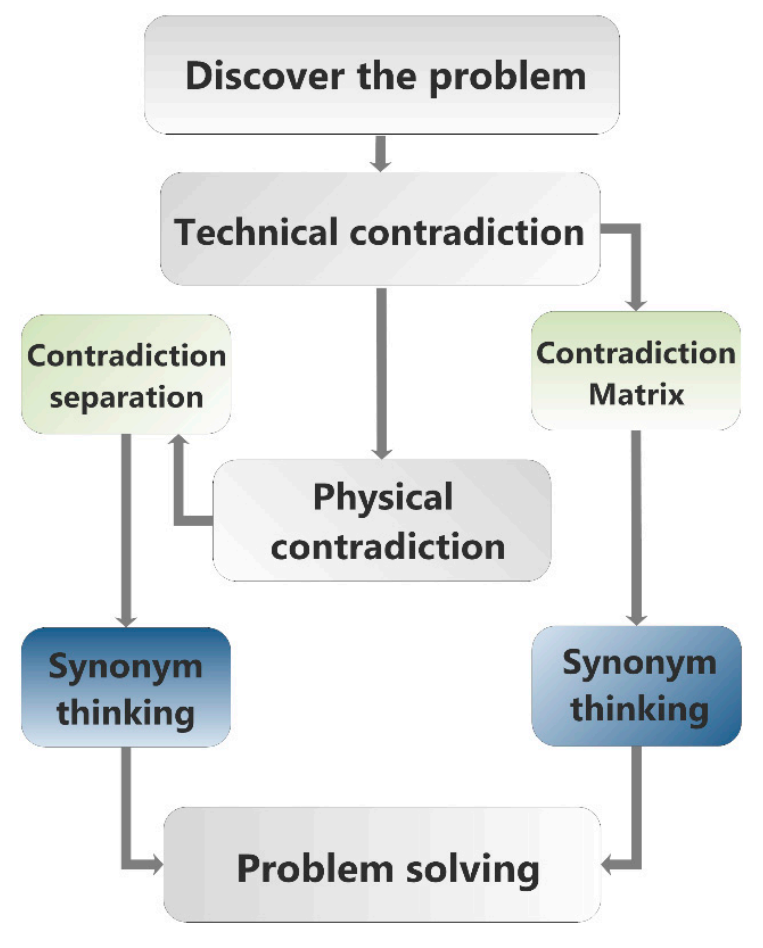

Figure 13. Flow chart of problem solving by contradiction.

Table 5. Contradiction matrix of assembly board.

\begin{tabular}{lcc}
\hline \multicolumn{1}{c}{ Worsening Feature } & \multirow{2}{*}{ 1. Weight of Moving Object } & 36. Device Complexity \\
Improving Feature & $19,5,34,31$ & $10,4,29,15$ \\
15. Duration of action of moving object & $35,6,18,31$ & $3,13,27,10$ \\
26. Quantity of substance/the matter & $1,6,15,8$ & $15,29,37,28$ \\
35. Adaptability or versatility & & \\
\hline
\end{tabular}

All of the inventive principles in this matrix are considered and discussed carefully according to the realistic conditions for Sumi-Hanel. We found that the most useful and feasible principles among them are \#5 and \#13, which are recommended due to advanced features.

\#5. Merging, meaning:

- Physically join or merge identical or related objects, operations, or functions.

- Join or merge objects, operations, or functions so that they act together in time.

\#13. The other way round pointed out ideas that:

- Use an opposite action(s) to solve the problem (e.g., instead of cooling an object, heat it).

- Make movable objects fixed, and fixed objects movable.

- Turn the object, system, or process "upside down". 
In this paper, the selected principles or solution concepts can serve as a design direction to improve and redesign the original product with innovative ideas. If any parameter of the contradiction matrix cannot be clearly identified after the problem formulations, it means it produces negative results. This paper suggests reselecting the best tool from the 40 principles and using it to find the most desired solution by applying the TRIZ problem solving tool.

\subsection{Generate the Solution}

Generate the solution is the third step of the TRIZ methodology and the stage where many options are generated by using TRIZ tools. In this paper, inventive principle \#5 (Merging) enumerates the differences between board type 1 and board type 2 . There are some differences in the distribution of the branches, as shown in Figure 14.
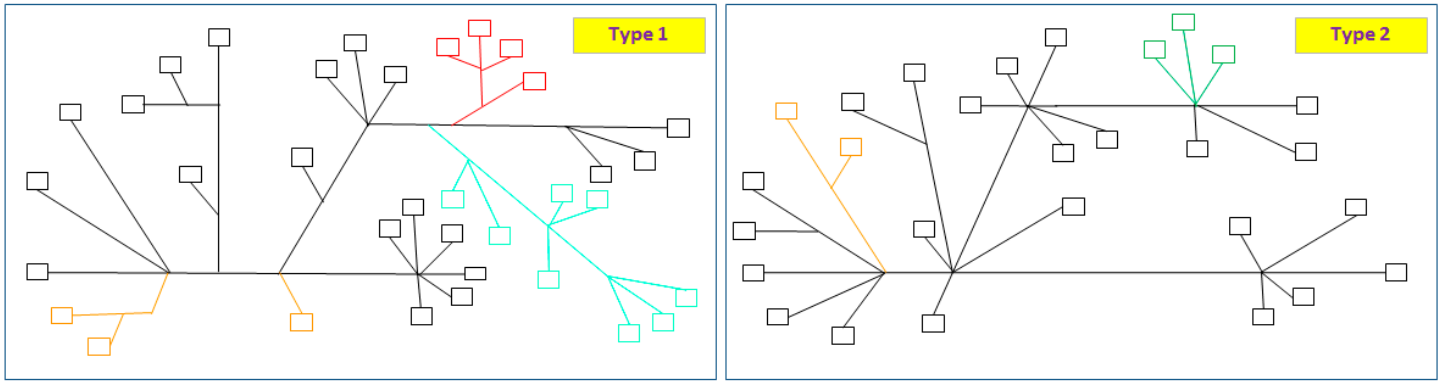

Figure 14. The diagram of assembly board types 1 and 2.

One frame can only support one board. However, inventive principle \#13 ("the other way round") gives a good suggestion: "turn the object, system, or process upside down." This means one frame can support two boards, and the boards can be rotated in order to be reserved when changing the type of product. Figure 15 presents the single board and the rotating board.
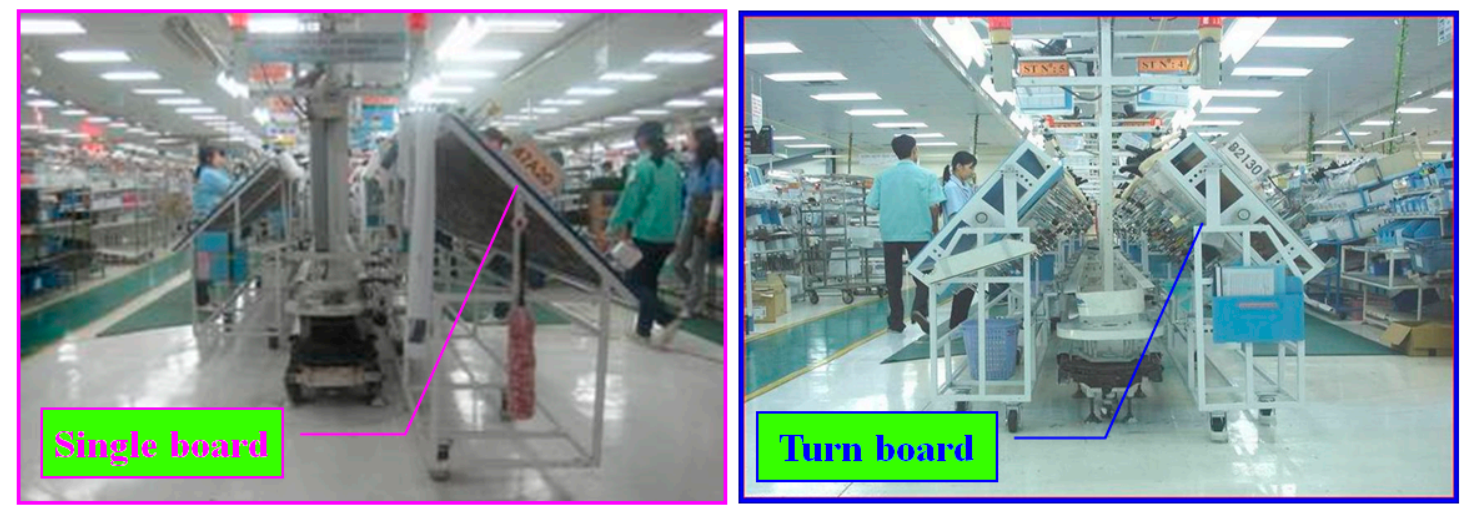

Figure 15. The single board and the rotating board.

The quantity of rotating frame $(X)$ that can bring two frames depends on the total quantity of boards $(Y)$ and the quantity of frames $(Z)$.

If $Y=Z$, it is not necessary to use a rotating frame. One frame supports one board.

If $Y>Z$, the rotating frame is used. The quantity of rotating frames is calculated by using the formula $X=Y-Z$.

If $Y=2 \times Z$ then $X=2 \times Z-Z=Z$, all the frames in the conveyor are rotating ones.

If $Y>2 \times Z$ then all the frames in the conveyor are rotating ones, but it is required to change boards using the old method. Table 4 indicates that $\operatorname{Max}(Y)=2 \times Z$, or this situation has never appeared. Therefore, it is not under consideration anymore. 
In this research, the Wagon engine conveyor is taken as an example:

The total quantity of boards is $Y=27$.

The total quantity of frames is $Z=20$.

The quantity of rotating frames is $X=Y-Z=27-20=7$ frames.

This means seven rotating frames are needed to solve the problem. The layout of boards is shown in Figure 16.
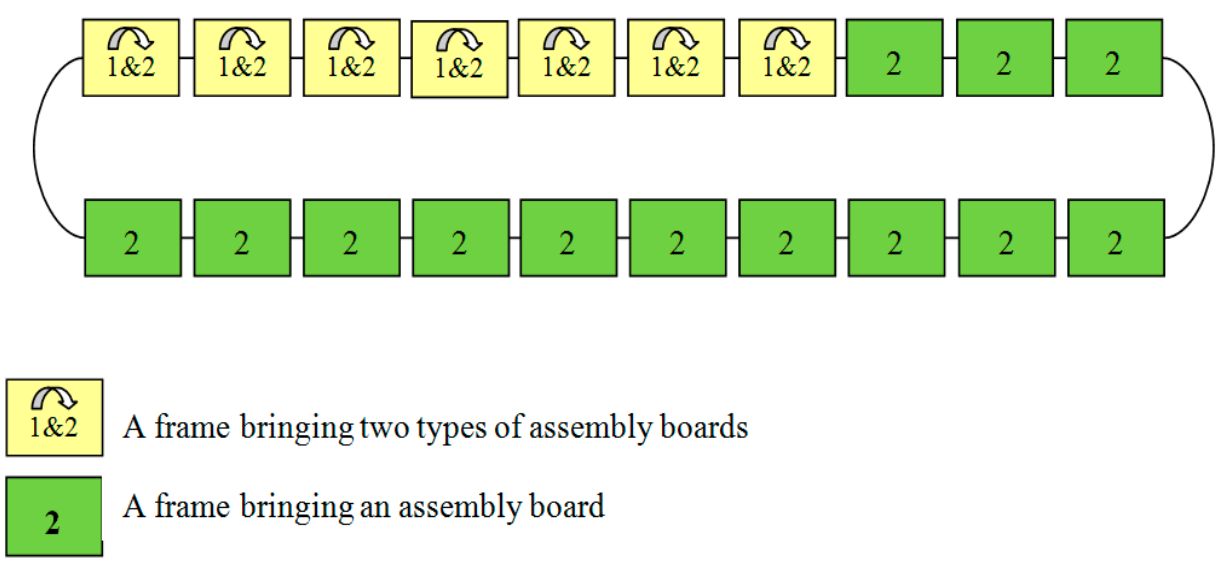

Figure 16. The new layout of assembly boards in the conveyor.

\subsection{Evaluation}

The final part of the systematic creativity process is the one associated with evaluating the solutions obtained during previous stages. In this paper, the problems of assembly boards are solved successfully by applying TRIZ methodology. This helps a company to save space, time, and money. The time for a board change is reduced by $10 \mathrm{~min}$ compared to the original time, which helps to speed up conveyor operation and productivity. This reduces the time spent changing boards by $67 \%$. Therefore, working overtime is not required and companies can save manpower and costs. Moreover, a waiting area for boards is not necessary anymore, because all the boards are carried by rotating frames. The space saved by eliminating one conveyor is 8400 square meters, which was used to store waiting boards. This is a significant improvement. Instead, these areas can be used to set up a new conveyor or increase capacity. Finally, the cost saved from not setting up new conveyors is at least $\$ 24,000$ (around $20 \%$ ), because the company can drive down the costs of labor and waste production. The aim of this study has been achieved and it can be evaluated as the best solution for improving manufacturing lines according to both quantitative and qualitative standards. Table 6 gives a comparison of this study before and after improvements.

Table 6. Comparison of the research results before and after improvement.

\begin{tabular}{ccccc}
\hline Items & Before & After & Evaluation & Improvement \\
\hline Free area for the new conveyors & $1400 \mathrm{~m}^{2}$ & $9800 \mathrm{~m}^{2}$ & Saved $8400 \mathrm{~m}^{2}$ & $600 \%$ \\
Time of changing board & $15 \mathrm{~min}$ & $5 \mathrm{~min}$ & Reduced by $10 \mathrm{~min}$ & $67 \%$ \\
Cost of setting up new conveyors & $\$ 120,000$ & $\$ 96,000$ & Saved $\$ 24,000$ & $20 \%$ \\
\hline
\end{tabular}

\section{Conclusions}

In the 1990s the automobile industry fell on hard times because of the Japanese asset price bubble and extreme currency appreciation. During the 2000s and up to the global economic crisis of 2008, most companies coped with the challenges. This paper proposes an innovative approach, combining TRIZ with lean manufacturing concepts, which can lead to continuous improvement in manufacturing lines and enhance sustainable development for companies. Besides that, it gives insights in terms 
of understanding the overview impact of a global economic recession and its specific consequences in Japan as is the automobile industry is key to the nation's economy. TRIZ, combined with lean manufacturing, was adopted by the authors and was found to outperform the traditional approaches. By correctly defining the problem, the solution to the problem can be found quickly. Define, select tool, generate solutions, and evaluate are the four major steps related to the systematic creativity and form a loop. When a problem is defined differently, different solutions and effects can be obtained. Therefore, this study suggests going through the steps more than once in order to obtain a better solution.

The power of TRIZ, with its analytical tools, is that it can be employed to identify the problems of an assembly board, while TRIZ technical tools can help to generate better ideals by using a contraction matrix and inventive principles. Furthermore, according to empirical analysis, the problems occurring at the replacing assembly board section undergo a big improvement when we apply the TRIZ approach. This research has contributed a new approach to solving the problem of supplier Sumi-Hanel. The study results successfully eliminate the wasted time spent changing a board, decreasing the original time schedule by $10 \mathrm{~min}$. Moreover, the more than 8000 square meters used as a waiting area for the assembly boards and old layout conveyor can also be saved. This gives the firm more space for setting up new conveyors and it runs more efficiently due to this technological enhancement. Therefore, the operators do not have to work overtime at weekends. The objective of this study has been successfully achieved.

As to the limitations of this research, the researchers would like to contribute to an overview of the Japanese automobile industry and accordingly implemented the integrated methodologies of lean manufacturing and TRIZ to give meaningful and helpful ideas about sustainable manufacturing for other companies in a variety of industries. However, two limiting factors were found in the empirical results: the quantity of boards $(\mathrm{Y})$ and frames $(\mathrm{Z})$. By using a rotating board, these problems were solved completely in this paper. However, in the future, if the conveyors use more types of board $(\operatorname{Max}(\mathrm{Y})>2 \times \mathrm{Z})$, then other papers should suggest different parameters and inventive principles in order to generate better solutions. This situation needs more time to analyze and it can be the topic for another study. For further study we also suggest investigating problems in other sections such as material coordination, cutting and crimping, etc. More methodologies can be applied to continuously improve the productivity in further studies.

Author Contributions: Chia-Nan Wang and Ying-Fang Huang designed the research and provided ideas; Thi-Nham Le analyzed the data and wrote the manuscript. Thanh-Tuan Nguyen collected data from Sumi-Hanel auto parts supplier and was involved in the results discussion. All authors have read and approved the final manuscript.

Conflicts of Interest: The authors declare no conflict of interest.

\section{Abbreviations}

The following abbreviations are used in this manuscript:

TRIZ Teoriya Resheniya Izobreatatelskih Zadatch

FAA function and attribute analysis

OEM original equipment manufacturer

PVC polyvinyl chloride

\section{References}

1. Benders, J. Leaving lean? Recent changes in the production organization of some Japanese car plants. J. Econ. Ind. Democr. 1996, 17, 9-38. [CrossRef]

2. Public Relations Office of Jama. The Motor Industry of Japan Yearbooks, 2005-2015; Japan Automobile Manufacturers Association Inc.: Tokyo, Japan, 2005-2015.

3. Japan Automobile Manufacturers Association Database. Available online: http://www.jama-english.jp/ statistics/production_export/2015/160129.html (accessed on 19 January 2016). 
4. Katsuhiro, S. The impact of the rise of Chinese and Indian automobile industries. Available online: http://conference.osu.eu/globalization/publ2011/286-291_Sasuga.pdf (accessed on 25 April 2016).

5. Donnelly, T.; Collis, C.; Begley, J. Towards sustainable growth in the Chinese automotive industry: Internal and external obstacles and comparative lessons. Int. J. Autom. Technol. Manag. 2010, 10, 289-304. [CrossRef]

6. Mair, A. Just-in-time manufacturing and the spatial structure of the automobile industry: Lesson from Japan. J. Econ. Soc. Geogr. 1992, 83, 82-92. [CrossRef]

7. Wang, C.N.; Nguyen, X.T.; Wang, Y.H. Automobile industry strategic alliance partner selection: The application of a hybrid DEA and grey theory model. Sustainability 2016, 8, 173. [CrossRef]

8. Katayama, H.; Bennett, D. Lean production in a changing competitive world: A Japanese perspective. Int. J. Oper. Prod. Manag. 1996, 16, 8-23. [CrossRef]

9. Li, T.S.; Huang, H.H. Applying TRIZ and Fuzzy AHP to develop innovative design for automated manufacturing system. Expert Syst. Appl. 2009, 36, 8302-8312. [CrossRef]

10. Nkomo, T. Analysis of Toyota Motor Cooperation; Harvard University: Cambridge, MA, USA, 2013.

11. Ng, D.; Vail, G.; Thomas, S.; Schmidt, N. Applying the lean principles of the Toyota production to deduce wait times in emergency department. CJEM 2010, 12, 50-57. [PubMed]

12. Wu, L.; Subramanian, N.; Abdulrahman, M.; Liu, C.; Lai, K.H.; Pawar, K.S. The impact of integrated practices of lean, green, and social management systems on firm sustainability performance-evidence from Chinese fashion auto-parts supplier. Sustainability 2015, 7, 3838-3858. [CrossRef]

13. Domingo, R.; Aguado, S. Overall environment equipment effectiveness as a metric of a lean and green manufacturing system. Sustainability 2015, 7, 9031-9047. [CrossRef]

14. Takahiro, F. Automobiles: Strategy-Based Lean Production System; Tokyo University: Tokyo, Japan, 2001.

15. Bayou, M.E.; Korvin, A. Measuring the leanness of manufacturing system-A case study of Ford Motor company and general motors. J. Eng. Technol. Manag. 2008, 25, 287-304. [CrossRef]

16. International Trade Administration. On the Road: U.S. Automotive Parts Industry Annual Assessment. Available online: http:/ /www.trade.gov/static/2011Parts.pdf (accessed on 19 January 2016).

17. Petrov, V. Timeline of the Development of TRIZ. Available online: http://www.triz-journal.com/ timeline-of-the-development-of-triz-and-genrich-altshuller/ (accessed on 19 January 2016).

18. Lean Manufacturing. Available online: http://www.lean-manufacturing-japan.com/ (accessed on 19 January 2016).

19. Melton, T. The benefits of lean manufacturing. J. Chem. Eng. Res. Des. 2005, 83, 662-673. [CrossRef]

20. Ohno, T. Toyota Production System, 2nd ed.; Institute of Industrial Engineers: Tokyo, Japan, 1994.

21. Womack, J.P.; Jones, D.T.; Ross, D. The Machine that Changed the World, 1st ed.; Rawson Associates: New York, NY, USA, 1990.

22. Womack, J.P.; Jones, D.T. From Lean Production to the Lean Enterprises, 1st ed.; Harvard Business Review: Brighton, MA, USA, 1994; pp. 93-103.

23. Kamath, R.R.; Liker, J.K. A Second Look at Japanese Product Development, 1st ed.; Harvard Business Review: Brighton, MA, USA, 1994; pp. 154-170.

24. Kim, J.H.; Lee, J.Y.; Kang, S.W. The acceleration of TRIZ propagation in Samsung electronics. In Proceedings of the TRIZ Future Conference, Seoul, Korea, 16-18 November 2005.

25. Lee, J.Y. TRIZ Activities at Samsung electronics. In Proceedings of the TRIZ Conference, Florence, Italy, 3-5 November 2004.

26. Adhikary, S.; Buktar, R.B. Product quality improved using TRIZ: A case study in increasing innovative options in manufacturing sector application of TRIZ to reduce of particulate matter in cleaned engine blocks. Int. J. Res. Eng. Technol. 2014, 3, 668-674.

27. Sergei, I. TRIZ as a lean thinking tool. In Proceedings of the ETRIA TRIZ Future Conference, Florence, Italy, 3-5 November 2004.

28. Savransky, S.D. Engineering of Creativity: Introduction to TRIZ Methodology of Inventive Problem Solving, 1st ed.; CRC Press: New York, NY, USA, 2000; pp. 199-228.

29. Mann, D. Hands-on Systematic Innovation, 1st ed.; CREAX Press: Ieper, Belgium, 2002.

30. Mann, D. Hans-on Systematic Innovation for Technical System, 2nd ed.; IFR Press: London, UK, 2007; pp. 101-117. 
31. Cheng, S.T.; Yu, W.D.; Wu, C.M.; Chiu, R.S. Analysis of construction inventive patents based on TRIZ. In Proceedings of the International Symposium on Automation and Robotics in Construction Conference, Tokyo, Japan, 3-5 October 2006.

32. Retseptor, G. 40 Inventive Principles in Quality Management. Available online: https://www.bmgi.com/ sites/bmgi.com/files/40\%20Inventive\%20Principles\%20in\%20Quality\%20Management.pdf (accessed on 25 April 2016).

33. Mann, D.; Domb, E. 40 Inventive Principles with Business Examples. Available online: http:/ /innomationcorp.com/Files/40\%20Inventive\%20Principles_Business_InnomationLLC_Rev2.pdf (accessed on 25 April 2016).

34. Zhang, J.; Chai, K.H.; Tan, K.C. 40 Inventive Principles with Applications in Service Operations Management. Available online: https://triz-journal.com/40-inventive-principles-applications-serviceoperations-management/ (accessed on 25 April 2016).

35. Altshuller, G. 40 Principles: TRIZ Keys to Technical Innovation, 1st ed.; Technical Innovation Center Inc.: Worchester, MA, USA, 1988.

36. Akay, D.; Demiray, A.; Kurt, M. Collaborative tool for solving human factors problems in the manufacturing environment: The theory of inventive problem solving technique (TRIZ) method. Int. J. Prod. Res. 2008, 46, 2913-2925. [CrossRef]

37. Lin, C.S.; Su, C.T. An innovative way to create new services: Applying the TRIZ methodology. J. Chin. Inst. Ind. Eng. 2007, 24, 142-152. [CrossRef]

38. Stratton, R.; Mann, D. Systematic innovation and the underlying principles behind TRIZ and TOC. J. Mater. Process. Technol. 2003, 139, 120-126. [CrossRef]

39. Amanda, B. The Overlap between TRIZ and Lean; University of Rhode Island: Kingston, RI, USA, 2006.

(C) 2016 by the authors; licensee MDPI, Basel, Switzerland. This article is an open access article distributed under the terms and conditions of the Creative Commons Attribution (CC-BY) license (http://creativecommons.org/licenses/by/4.0/). 